\title{
Integrating alcohol risk reduction into HTC services
}

Population Council

Follow this and additional works at: https://knowledgecommons.popcouncil.org/departments_sbsr-rh

Part of the International Public Health Commons, Social and Behavioral Sciences Commons, and the Substance Abuse and Addiction Commons

How does access to this work benefit you? Let us know!

\section{Recommended Citation}

"Integrating alcohol risk reduction into HTC services," APHIA II Operations Research Project in Kenya OR Summary. Nairobi: Population Council, 2011. 
up?") were sent out and clients replied "Poa" (meaning fine) or "Shida" (meaning there was a problem and provider then called). The number of messages sent and replied can be seen in the graph below. In round 1 , 65\% HCT clients were reached with an SMS message and round 4, nearly all (97\%) were reached.

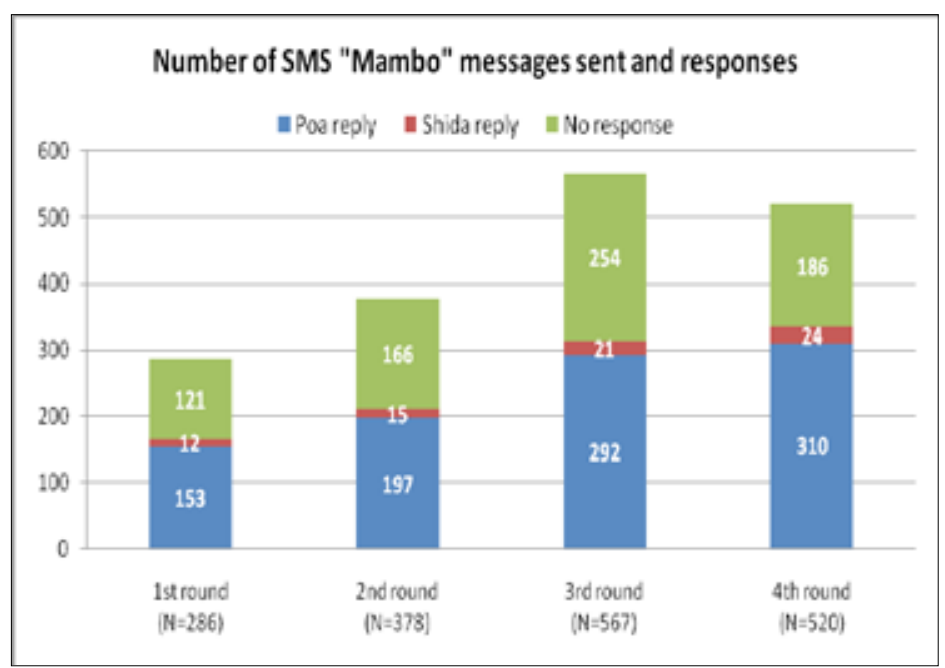

- The proportion of respondent reporting to seek treatment for their alcohol addiction increased from $13 \%$ to $34 \%$ between baseline and endline evaluations $(\mathrm{p}<0.001)$.

- Heavy drinking behaviors generally declined and the proportion of people currently drinking fell from $98 \%$ to $74 \%$. Fewer people

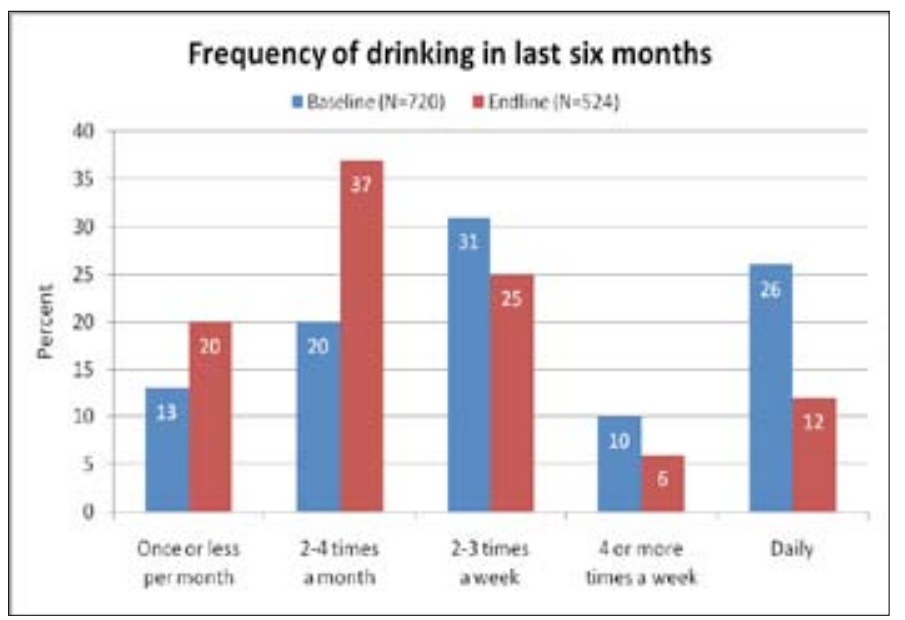

reported drinking 2 to 3 times a week or more $(67 \%$ to $43 \%)$; and daily drinking declined from $26 \%$ to $12 \%$ during the intervention. The number of people reporting drinking 4 times a month or less increased ( $33 \%$ to $57 \%$ ).

- At endline, there was an increase in the proportion of clients reporting a small number of sexual partners (i.e. 1 to 4 partners) in last 6 months and a reduction in the proportion reporting a high number ( 5 or more partners). The proportion reporting frequently having sex while drunk also reduced from $33 \%$ to $14 \%$. These changes imply an overall reduction in risky sexual practices among those followed during the six month period.

The lack of control group in the evaluation design hindered the ability to draw direct causality between the intervention and changes observed in drinking and sexual behaviors. Nonetheless, findings are most likely associated with implementation of this program, as treatment and counseling services were not widely available beforehand.

\section{Conclusions}

- Screening of HTC clients for alcohol abuse and referral to active support and counseling services is feasible

- Using SMS is a successful methodology to follow-up and check in with such a high-risk population.

April, 2011

1 CAGE is an acronym of four questions in a screening tool that focus on Cutting down, Annoyance by criticism, Guilty feelings, and Eye-opener. Two or more "yes" responses on the CAGE screening tool indicated that one has problems with alcohol (i.e., Cage-positive). 